\title{
Prevalence, Fertility, and Viability of Cystic Echinococcosis in Cattle Slaughtered at Adaba Abattoir, West Arsi Zone, Ethiopia
}

\author{
Kirubel Paulos Gutama1, Mahendra Pal ${ }^{*} \mathbb{D}$ \\ ${ }^{1}$ Adaba woreda Livestock and Fishery Resource, Development Office, Adaba, West Arsi, Ethiopia \\ ${ }^{2}$ Narayan Consultancy on Veterinary Public Health and Microbiology, Gujarat, India
}

\begin{abstract}
Introduction: Cystic echinococcosis is a zoonotic infection caused by larval stage of Echinococcus granulosus, which is a widely prevalent disease of public health and economic importance. This cross-sectional study was undertaken from January to July 2019 in Adaba abattoir to estimate the prevalence of cystic echinococcosis, investigate its potential risk factors, and to characterize the cysts.

Materials and Methods: A total of 400 samples were collected and processed. The study animals were chosen using a simple random sampling method. Potential risk factors were assessed by ante-mortem examination. A post-mortem examination was also performed, which included a primary examination (visual inspection and palpation of the lung, liver, heart, spleen, and kidney) and a secondary examination (incisions into each organ in the presence of one or more hydatid cysts). The total number of cysts found per organ and their sizes were recorded. The prevalence of cystic echinococcosis was summarized using descriptive statistics, and the chi-square test was used to assess infection status in relation to the hypothesized risk factors. A probability level of $P<0.05$ was set for statistical significance.

Results: The overall prevalence of cystic echinococcosis was recorded to be $34.5 \%$ (95\% Cl: 14.69-22.90). The disease was statistically significantly $(P<0.05)$ associated with age and body condition scores, but insignificantly $(P 3>0.05)$ associated with gender. Of the total of infected cattle, a large number of cysts were found in lung $60(35.7 \%)$. After characterization of the cysts based on size, $69(48.9 \%), 62(43.9 \%)$, and $10(7.1 \%)$ cysts were categorized as small, medium, and large, respectively. Of the total cysts examined, 27 (16\%) were calcified, 101 (60.1\%) were sterile, and $33(23.9 \%)$ were fertile. Out of the total fertile cysts identified, 25 (62.5\%) were found to be viable and 15 (37.5\%) were non-viable cysts.

Conclusion: It is deduced that cystic echinococcosis is widespread in cattle slaughtered and it is a major cause of organ condemnation at Adaba abattoir. Therefore, it is imperative that efficient meat inspection service and safe disposal of condemned organs should be meticulously practiced in order to control this parasitic zoonosis.

Keywords: Prevalence, Cystic, Fertility, Cystic echinococcosis, Risk factors, Adaba, Abattoir, Ethiopia
\end{abstract}

Received: September 14, 2020, Accepted: December 25, 2020, ePublished: January 1, 2021

\section{Introduction}

Echinococcosis (hydatid disease, hydatidosis) is an important emerging and re-emerging helminthic zoonosis of worldwide distribution which is caused by Echinococcus granulosus, Echinococcus multilocularis, Echinococcus oligarthrus, and Echinococcus vogeli $(1,2)$ The disease has been recorded in humans as well as in many species of animals (1-3). The disease has significant impact on human health (4). The larval stage of Echinococcus granulosus is responsible for cystic echinococcosis (3). It is found all over the world including Ethiopia $(3,5)$. Cystic echinococcosis is more common, has a higher economic cost, and exerts greater public health impact in rural communities in developing nations where dogs, intermediate host species, and humans interact (6). The disease contributes to reduced meat production due to carcass or organ condemnation (7). The failure of organs caused by cysts, as well as anaphylaxis caused by the cyst bursting and releasing fluid, is a serious manifestation in humans (8).

To complete its life cycle, Echinococcus requires two mammalian hosts (an intermediate and a definitive host) (9). Although dogs are the most common definitive host of the parasite, the parasite can also live in intermediate hosts, such as domestic ungulates and humans (10). The gravid proglottids of the adult worm release eggs in the small intestine, which the definitive host passes in feces. Intermediate hosts, such as cattle, sheep, goats, pigs, and 
other ruminants, as well as humans, can accidentally ingest these infective eggs with oncosphere. The eggs hatch in the small intestine of the intermediate host, and the released oncospheres breach the intestinal wall and travel through the circulatory system to a variety of organs, including the liver and lungs (11).

In areas where cattle, sheep, and goats are still slaughtered traditionally and offal is widely accessible to dogs and other wild carnivores, cystic echinococcosis is potentially a zoonotic disease (12). The disease is endemic in livestock-rearing areas around the world, creating public health problems in regions such as the Middle East, Mediterranean region, Central and South America, Asia, and Africa (13). Since the 1970s, Ethiopians have been reporting the condition, and it is one of the primary causes of organ condemnation in most abattoirs and slaughterhouses, resulting in huge financial losses (14).

Several studies have reported the prevalence and economic significance of cystic echinococcosis in different abattoirs of Ethiopia, such as, Bahir Dar municipal abattoir (18.75\%) (15), Kombolcha abattoir (33.5\%) (5), Jimma abattoir (54.5\%) (16) and Asella municipal abattoir (37.9\%) (17). Despite the foregoing studies, the disease has not been well investigated, and information on its prevalence, economic impact, and associated risk factors is still inadequate, particularly in and around Adaba. Furthermore, having sufficient information regarding the prevalence of the disease and its related risk factors in the research area is critical for developing an appropriate preventative and control approach. Therefore, this study was conducted with the objectives to estimate the prevalence of cystic echinococcosis, investigate its potential risk factors, and characterize the cysts in cattle subjected to slaughter at Adaba abattoir in Ethiopia.

\section{Materials and Methods Study Area Description}

Adaba is a town in west Arsi Zone of Oromia regional state of Ethiopia. It is located at $250 \mathrm{~km}$ south-west of Addis Ababa (capital city of Ethiopia), between latitudes $7^{\circ} 00^{\prime} 0.00^{\prime \prime} \mathrm{N}$ and $39^{\circ} 29^{\prime} 59.99^{\prime \prime} \mathrm{E}$. Adaba is bordered on the southwest by Nensebo, on the west by Dodola, on the northwest by Shabelle river, which separates it from the Gedeb-Asasa, and on the east and south by Bale Zone. The average maximum temperature of Adaba is $21^{\circ} \mathrm{C}$, while the average minimum temperature is $10.4^{\circ} \mathrm{C}$. According to a land survey, $16.9 \%$ of this woreda is arable or cultivable, $23.3 \%$ is pasture, $52.2 \%$ is forest, and the remaining $7.6 \%$ is considered swampy, mountainous or otherwise unusable. The Adaba abattoir provides fresh meat for different organizations such as hotels, restaurants, and butchers (18).

\section{Study Animals}

The study animals were crossbred and indigenous zebu cattle breeds of both genders were slaughtered at Adaba abattoir. The majority of the slaughtered animals were brought in from various markets in and around Adaba. It was difficult to pinpoint the origin of all animals slaughtered at the abattoir and relate the findings on hydatidosis to a specific location. Attempts were made, however, and it was discovered that the majority of them were obtained from nearby markets (Dodola, Bale-Robe and Gadab-Asasa).

\section{Study Design}

This study was a cross-sectional study conducted in Adaba abattoir from January to July 2019 to estimate the prevalence of cystic echinococcosis, investigate its potential risk factors, and characterize the cysts, taking into account the age, gender, and body condition of the animal.

\section{Sample Size Determination}

The sample size was calculated using the formula recommended by Thrusfield and Christley (19), based on a $50 \%$ expected prevalence with $95 \%$ confidence interval (CI), and 5\% desired absolute precision.

$n=\frac{1.96^{2} p(1-p)}{d^{2}}$

Where, $\mathrm{n}=$ sample size of the study population, $\mathrm{d}=$ desired precision and $\mathrm{p}=50 \%$ expected prevalence.

Accordingly, based on the above formula, a sample size of 384 was calculated, but the sample size was increased to 400 to increase the level of precision.

\section{Sampling Method}

In the lairage, a simple random sampling procedure was used to select the required number of study animals. Female cattle were few in number in the research area; therefore, they were all included. Each selected animal was given an identification number and data on its gender, age, and body condition was recorded prior to sampling. The Ethiopian Ministry of Agriculture Meat Inspection Regulation (1972) was followed for inspecting meat for hydatid cysts.

\section{Data Collection Methods}

\section{Ante-mortem Examination}

Each of the study animals was given an identification number with a paint mark on their body during antemortem inspection. The age of the animals was estimated by examining the eruption of their teeth (20). Two age groups considered: those over the age of five and those under the age of five. On the basis of muscle mass and fat cover on the ribs, hips, between hooks, pins, spine, and transverse processes, body condition of the study animals were divided into three basic categories: poor, medium, and $\operatorname{good}(21)$. 


\section{Post-mortem Examination}

The post-mortem examination technique consisted of two steps: primary and secondary examinations. The visceral organs, such as lungs, liver, heart, spleen, and kidneys were visually inspected and palpated during the primary examination, which was followed by a subsequent examination if evidence of metacestode was found. The secondary examination involved further incision into each organ in the presence of one or more hydatid cyst(s). The total number of cysts found per organ and their sizes were all documented. The cysts were removed, packed in separate plastic bags, labeled, and transported to the laboratory for further analysis. The identification of cysts was carried out in Veterinary Clinic Laboratory of Adaba Woreda using the criteria described by Solusby (22).

\section{Cyst Characterization}

The cysts were counted, measured in size, and their fertility and viability were determined. They were categorized as large (diameter $>10 \mathrm{~cm}$ ), medium (diameter $5-10 \mathrm{~cm}$ ), or small (diameter $5 \mathrm{~cm}$ ) based on the size (23). Additionally, they were identified and classed as fertile or infertile based on the presence or absence of brood capsules containing protoscolices in hydatid fluid. Infertile cysts were further classified as sterile (fluid-filled cysts without protoscoleces) or calcified (typical calcified cysts produce a gritty sound when cut) (22). To test the viability, a needle was used to puncture the cyst wall, after which the contents were examined microscopically $(\times 40)$ for amoeboid-like peristaltic movement of protoscoleces, as per standard procedure. In doubtful circumstances, a drop of $0.1 \%$ aqueous eosin solution was added to an equal volume of viable protoscolices on a microscope slide, with the principle that viable protoscolices totally or partially exclude the dye, whereas dead protoscolices take it up (24).

\section{Data Analysis}

All data were collected and entered into a computer using Microsoft Excel before being transferred to STATA version 14.0 (Stata Corp. College Station, TX, USA) for analysis. The prevalence of cystic echinococcosis was calculated using descriptive statistics. The infection status was assessed in relation to the hypothesized risk factors using the chi-square test. A probability level of $(P<0.05)$ was set for statistical significance.

\section{Results}

Of the 400 cattle examined during routine meat inspection at Adaba Abattoir, 137 (34.25\%) (95\% CI: 29.74-39.06) were found to have cystic echinococcosis. The infection rate among the cattle with different body condition scores was shown to be significantly different $(P<0.05)$ in this study. The highest prevalence was found in the cattle with the poor body condition (50.8\%), followed by medium (22\%), and good (19.7\%) (Table 1).

There was a statistically significant difference in the infection rate among animals of different age groups $(P<0.05)$ in this study, with the highest prevalence in animals aged $>5$ years $(37.7 \%)$ and the lowest prevalence in animals aged $\leq 5$ years (24\%) (Table 2 ).

There was a statistically significant difference in the infection rate among studied animals of different genders $(P>0.05)$ in the current study, with male animals having a higher prevalence $(34.8 \%)$ than female animals (30.8\%) (Table 3).

Of the 137 infected cattle, 168 cysts were identified, among which $60(35.7 \%)$ cysts were found only in the lung, $40(23.8 \%)$ were found only in the liver, $1(0.6 \%)$ was found in the spleen, $4(1.8 \%)$ were found in the kidney, 3 $(1.8 \%)$ were found in the heart, $52(30.9 \%)$ were found both in the liver and lung, $6(3.6 \%)$ were found in the liver, lung, and heart at the same time, and $3(1.8 \%)$ were found

Table 1. The Prevalence of Cystic Echinococcosis in Cattle Slaughtered at Adaba Abattoir in Relation to Their Body Condition

\begin{tabular}{lccccc}
\hline Variables & Categories & Animal Examined & No. of Positive Cases & Prevalence $(\%)$ & 50.9 \\
\hline \multirow{3}{*}{ Body condition } & Poor & 175 & 89 & $\chi^{2}$ & 38.21 \\
& Medium & 159 & 35 & 13 & 19.7 \\
\hline
\end{tabular}

Table 2. The Prevalence of Cystic Echinococcosis in Cattle Slaughtered at Adaba Abattoir in Relation to their Age

\begin{tabular}{lcccccc}
\hline Variable & Categories & Animal Examined & No. of Positive Cases & Prevalence (\%) & $\chi^{2}$ & $\boldsymbol{P}$ Value \\
\hline Age & $\leq 5$ years & 100 & 24 & 24 & 6.22
\end{tabular}

Table 3. The Prevalence of Cystic Echinococcosis in Cattle Slaughtered at Adaba Abattoir in Relation to their Gender

\begin{tabular}{lcccccc}
\hline Variable & Categories & Animal Examined & No. of Positive Cases & Prevalence (\%) & $\boldsymbol{\chi}^{2}$ & \multicolumn{2}{c}{$\boldsymbol{P}$ Value } & 34.8 & 0.32 \\
\hline Gender & Male & 348 & 121 & 16 & 30.8 & 0.571 \\
\hline
\end{tabular}


in the liver, lung, and kidney at the same time (Table 4).

After characterization of the cysts based on size, 69 (48.9\%), 62 (43.9\%) and 10 (7.1\%) were categorized as small, medium, and large, respectively, without including calcified cysts. The distribution of cysts in different organs based on size revealed that the lung had the highest number of small, medium, and large cysts (Table 5).

Of the total cysts examined, 27 (16\%) were calcified, 101 (60.1\%) were sterile, and 40 (23.9\%) were fertile. Out of the total fertile cysts identified, 25 (62.5\%) were found to be viable and $15(37.5 \%)$ were nonviable cysts. Out of the total 40 fertile cysts recorded,

Table 4. The Location of Cystic Echinococcosis in Cattle Slaughtered at Adaba Abattoir

\begin{tabular}{lcc}
\hline Organ & $\begin{array}{c}\text { Number of Organs } \\
\text { Affected }\end{array}$ & Percent \\
\hline Lung & 60 & 35.7 \\
Liver & 40 & 23.8 \\
Spleen & 1 & 0.6 \\
Kidney & 3 & 1.8 \\
Heart & 3 & 1.8 \\
Lung and liver & 52 & 30.9 \\
Lung, liver and heart & 6 & 3.6 \\
Lung, liver and kidney & 3 & 1.8 \\
\hline
\end{tabular}

Table 5. Distribution of Hydatid Cysts Based on Size in Different Organs of Cattle at Adaba Abattoir

\begin{tabular}{lcccc}
\hline Organ & $\begin{array}{c}\text { Small cyst } \\
(\mathbf{\%})\end{array}$ & $\begin{array}{c}\text { Medium } \\
\text { cyst }(\mathbf{\%})\end{array}$ & $\begin{array}{c}\text { Large cyst } \\
\mathbf{( \% )}\end{array}$ & $\begin{array}{c}\text { Total } \\
\mathbf{( \% )}\end{array}$ \\
\hline Lung & $35(50.7)$ & $40(64.5)$ & $7(70)$ & $82(58.2)$ \\
Liver & $26(37.7)$ & $21(33.9)$ & $3(30)$ & $50(35.5)$ \\
Spleen & - & $1(1.6)$ & - & $1(0.7)$ \\
Heart & $5(7.2)$ & - & - & $5(2.8)$ \\
kidney & $3(4.3)$ & - & - & $3(2.8)$ \\
Total & $69(48.9)$ & $62(43.9)$ & $10(7.1)$ & 141 \\
\hline
\end{tabular}

$15(37.5 \%)$ were found in the lung, 9 (22.5\%) in the liver, 1 (2.5\%) in the kidney, $1(2.5 \%)$ in the spleen, and $14(35 \%)$ in the lung and liver. Of 101 sterile cysts recorded, $41(40.6 \%)$ were found in the lung, $15(14.8 \%)$ in the liver, $1(0.9 \%)$ in the kidney, 3 (2.9\%) in the heart, 32 (31.7\%) in the lung and liver, 6 (5.9\%) in the lung, liver, and heart, and 3 (2.9\%) in the lung, liver, and kidney. Of the total 27 calcified cysts, 4 (14.8\%) were found in the lung, $16(59.2 \%)$ in the liver, 1 (3.7\%) in the kidney, and 6 (22.2) in the lung and liver (Table 6).

\section{Discussion}

Cystic echinococcosis, caused by larval stage of E. granulosus, is a neglected helminthic zoonosis of worldwide distribution (3). The present study reported the occurrence of cystic echinococcosis in cattle of different body condition scores, age groups, and genders that were slaughtered at Adaba abattoir in Ethiopia. The overall prevalence of cystic echinococcosis was estimated to be $34.25 \%$ (137/400). Our observation is comparable with reports of studies conducted in Asella abattoir (37.9\%) (17) and Kombolcha abattoir (33.5\%) (5). The infection rate found in the present study is lower when compared with studies conducted in Shashamanne abattoir (49.5\%) (25) and Jimma abattoir (54.5\%) (16). However, it is higher compared to the reports of studies conducted in Bako abattoir (11.8\%) (26) and Gondar Elfora export abattoir (20.5\%) (27). The differences in the prevalence of cystic echinococcosis among cattle in different areas of Ethiopia could be due to a range of factors, including agroecology, public awareness, and culture and religion of the society.

In the present study, body condition showed statistically significant $(P<0.05)$ association with the prevalence of cystic echinococcosis. The infection rate was significantly higher in animals having poor body condition than medium and good body conditioned animals. Our finding is in accordance with the studies conducted in Adama municipal abattoir (28) and Jimma abattoir (16). Because of their low immunity, animals with poor body condition had a higher chance of infection with cystic echinococcosis. It is also possible that the animals who were in poor body condition had previously suffered from dietary and health issues.

Table 6. Fertility and Viability of Cysts in Different Organs

\begin{tabular}{|c|c|c|c|c|c|}
\hline \multirow{2}{*}{ Organ } & \multicolumn{3}{|c|}{ Fertility Test } & \multicolumn{2}{|c|}{ Viability TEST } \\
\hline & Fertile (\%) & Sterile (\%) & Calcified (\%) & Viable $(\%)$ & Non-viable viable $(\%)$ \\
\hline Lung & $15(37.5)$ & $41(40.6)$ & $4(14.8)$ & $10(40)$ & $5(33.3)$ \\
\hline Liver & $9(22.5)$ & $15(14.8)$ & $16(59.2)$ & $6(24)$ & $3(20)$ \\
\hline Kidney & $1(2.5)$ & $1(0.9)$ & $1(3.7)$ & - & $1(6.6)$ \\
\hline Heart & - & $3(2.9)$ & - & - & - \\
\hline Spleen & $1(2.5)$ & - & - & $1(4)$ & - \\
\hline Lung and liver & $14(35)$ & $32(31.7)$ & $6(22.2)$ & $8(32)$ & $6(40)$ \\
\hline Lung, liver, and heart & - & $6(5.9)$ & - & - & - \\
\hline Lung, liver, and kidney & - & $3(2.9)$ & - & - & - \\
\hline Total & $40(23.8)$ & $101(60.1)$ & $27(16.1)$ & $25(62.5)$ & $(37.5)$ \\
\hline
\end{tabular}


In the current study, with regard to the infection rate of cystic echinococcosis in different age groups of cattle, a significant difference $(P<0.05)$ was observed. Animals with more than 5 years of age were significantly more affected compared to those with less than 5 years of age. This finding is similar to the observations reported in Debre Berhan municipal abattoir (29) and Hawassa municipal abattoir (30). It is possible that the difference in infection rates is due to older cattle being exposed to infection for longer periods of time and having lower immunity to infection.

In the present study, there was a statistically insignificant $(P>0.05)$ association between gender and the prevalence of cystic echinococcosis. However, male animals were more affected than females. This observation is similar to the findings of studies conducted in Bako abattoir (26) and Debre Tabor abattoir (31). This may be due to the small number of female animals slaughtered at the abattoir during the study period. However, the current finding disagrees with observations reported in Debre Berhan municipal abattoir (29) and Adama municipal abattoir (28), where infection rate was statistically significantly associated with gender.

With regard to the location of the cysts, lung is found to be the most commonly affected organ followed by liver. The heart, kidney and spleen were the least affected organs in the study animals. This observation is in accordance with the findings of studies conducted in Adama municipal abattoir (28) and selected commercial abattoirs in Ethiopia (32). This could be because migrating oncospheres of the parasite come into contact with the liver and lung due to the presence of the dense capillary networks in these organs, and they are primarily exposed to the hepatic and pulmonary filtering systems before they come into contact with any other peripheral organ (33). Furthermore, the hexacanth embryo can penetrate the lymphatic system and travel via the thoracic duct to the heart and lungs, infecting the lung before or instead of the liver (34).

The proportion of large, medium, and small sized cysts was higher in the lung than in the other organs. Similar findings were reported in eastern parts of Ethiopia (35) and Wolaita Sodo municipal abattoir (36). The findings of this study revealed that most of the cysts found in cattle were sterile, followed by fertile and calcified cysts. This observation is similar to reports of studies conducted in Shashamanne abattoir (25) and Addis Ababa abattoir enterprises (37). The lung had a higher percentage of sterile cysts, while the liver had a higher percentage of calcified cysts. This could be linked to the higher reticuloendothelial cell count and abundant connective tissue reaction of the organ (38). The percentage of viable cysts was found to be higher in the lung. This could be due to the softer consistency of the lung, which allows easier development of the cyst, and the fertility of hydatid cyst may increase (39).

\section{Conclusion}

Cystic echinococcosis is widespread in slaughtered cattle, which is the leading cause of organ condemnation at the
Adaba abattoir. The highest number of cysts was found in the lung and liver, which could contribute to a higher rate of condemnation of these organs. The presence of viable cysts in the examined organs suggests that cattle continue to play a part in this zoonosis, posing a risk of transmission to other intermediate hosts and the human population of the study area. Furthermore, the estimated annual economic losses caused by cystic echinococcosis were reported in this study. Cystic echinococcosis appears to be an economically important disease in the study area, owing to the increased incidence of the disease in cattle and the resulting financial losses. As a result of the foregoing conclusion, the following recommendations are made:

- Efficient meat inspection service is imperative.

- Dogs should be dewormed, and condemned organs should be safely disposed

- It is essential to educate the public about cystic echinococcosis.

- In various parts of Ethiopia, detailed epidemiological investigations of cystic echinococcosis are required.

\section{Conflict of the Interests}

The authors declare that they do not have conflict of interest.

\section{Acknowledgments}

The authors are very thankful to Prof. Dr. R. K. Narayan for his recommendations during preparation of the manuscript and Anubha Priyabandhu for help with the computer. We dedicate our research paper to all the scientists who contributed to the field of parasitic zoonoses.

\section{Authors' Contributions}

Both Authors contributed equally. They read the final version and approved it for publication.

\section{Funding}

There was no financial support for this manuscript

\section{References}

1. Pal M. Zoonoses. 2nd ed. Jaipur, India: Satyam Publishers; 2007.

2. Pal M, Dutta JB. Echinococcosis: an emerging and re-emerging cyclozoonosis of global importance. Int J Livest Res. 2013;3(3):5-13. doi: 10.5455/ ijlr.20130929085504

3. Pal M, Zenebe N, Woldemariam T, Berhanu G. Prevalence of cystic echinococcosis in various food animals slaughtered at selected abattoirs in Ethiopia. Vet Res Int. 2020;8(3):118-23.

4. Garedaghi Y, Bahavarnia SR. Seroepidemiology of human hydatidosis by ELISA method in EastAzarbaijan province in Iran in year 2009. Iran J Epidemiol. 2011;7(2):25-9.

5. Nasr W, Pal M. Prevalence, cyst viability, fertility and 
economic significance of bovine hydatidosis in an abattoir at Kombolcha, Ethiopia. Haryana Vet. 2016;55(1):17-22.

6. Romig T, Omer RA, Zeyhle E, et al. Echinococcosis in sub-Saharan Africa: emerging complexity. Vet Parasitol. 2011;181(1):43-7. doi: 10.1016/j.vetpar.2011.04.022

7. Regassa F, Molla A, Bekele J. Study on the prevalence of cystic hydatidosis and its economic significance in cattle slaughtered at Hawassa municipal abattoir, Ethiopia. Trop Anim Health Prod. 2010;42(5):977-84. doi: 10.1007/ s11250-009-9517-2

8. Ethiopian Society of Animal Production (ESAP). Ruminants Livestock Development Strategy. Ethiopian Society of Animal Production, Addis Ababa Proceedings; $1995 ; 3: 1$

9. Parija S. Textbook of Medical Parasitology: Protozoology \& Helminthology. 2nd ed. New Delhi, India: ‘ All India Publishers \& Distributors; 2004.

10. Eckert J, Deplazes P. Biological, epidemiological, and clinical aspects of echinococcosis, a zoonosis of increasing concern. Clin Microbiol Rev. 2004;17(1):107-35. doi: 10.1128/cmr.17.1.107-135.2004

11. John D, William T, William P, Markell A, Edward K, Marietta V. The cestodes: E. granulosus, E. multiloularis and E. vogeli (Hyatid Disease). In: Markell \& Voge's Medical Parasitology. Elsevier Health Sciences; 2006.

12. Esubalew M. Study of Bovine Fasciolosis and Hydatidosis at Jimma, Western Ethiopia [thesis]. Bishoftu, Ethiopia: Addis Ababa University; 2003.

13. Shambesh MA, Craig PS, Macpherson CN, Rogan MT, Gusbi AM, Echtuish EF. An extensive ultrasound and serologic study to investigate the prevalence of human cystic echinococcosis in northern Libya. Am J Trop Med Hyg. 1999;60(3):462-8. doi: 10.4269/ajtmh.1999.60.462

14. Getaw A, Beyene D, Ayana D, Megersa B, Abunna F. Hydatidosis: prevalence and its economic importance in ruminants slaughtered at Adama municipal abattoir, central Oromia, Ethiopia. Acta Trop. 2010;113(3):221-5. doi: 10.1016/j.actatropica.2009.10.019

15. Tadesse M, Tesfaye S, Admasu P. Prevalence of bovine hydatidosis and its economic importance in cattle slaughtered at Bahir Dar municipal abattoir, northern Ethiopia. Int J Livest Res. 2016;6(10):1-10. doi: 10.5455/ ijlr.20160717032536

16. Temam A, Deresa B, Abdurahaman M. Study on prevalence and monetary loss attributed to hydatidosis in cattle slaughtered at Jimma municipal abattoir, southwestern Ethiopia. Glob J Med Res. 2016;16(2):17-24.

17. Genemo K, Elemo K, Haji F, Desu M. Bovine hydatidosis: prevalence and economic significance at Asella municipality abattoir, Asella, south eastern Ethiopia. Eur J Biol Sci. 2018;10(4):102-11. doi: 10.5829/idosi.ejbs.2018.102.111

18. AWAO (Adaba Woreda Agricultural Office). Annual Report. 2019.

19. Thrusfield M, Christley R. Veterinary Epidemiology. 4th ed. London: Wiley-Blackwell; 2018.

20. de Lahunta A, Habel RE. Applied Veterinary Anatomy. USA: Saunders; 1986.

21. Nicholson MJ, Butterworth MH. A Guide to Condition Scoring of Zebu Cattle. Addis Ababa, Ethiopia: International Livestock Centre for Africa (ILCA); 1986.
22. Solusby EJ. Helminthes, Arthropods and Protozoa of Domestic Animals. 7th ed. USA, Philadelphia: Lea and Fibiger; 1982.

23. Oostburg BF, Vrede MA, Bergen AE. The occurrence of polycystic echinococcosis in Suriname. Ann Trop Med Parasitol. 2000;94(3):247-52. doi: 10.1080/00034980050006429

24. Macpherson CN, Zeyhle E, Romig T. An Echinococcus pilot control programme for north-west Turkana, Kenya. Ann Trop Med Parasitol. 1984;78(3):188-92. doi: 10.1080/00034983.1984.11811798

25. Negash K, Beyene D, Kumsa B. Cystic echinococcosis in cattle slaughtered at Shashemanne municipal abattoir, south central Oromia, Ethiopia: prevalence, cyst distribution and fertility. Trans R Soc Trop Med Hyg. 2013;107(4):229-34. doi: 10.1093/trstmh/trt003.

26. Haftu B, Kebede T. Study on prevalence and economic significance of bovine hydatidosis in Bako municipal abattoir, west Shoa zone, Oromiya regional state. J Vet Sci Technol. 2014;5(5):197. doi: 10.4172/2157-7579.1000197

27. Abebe A, Beyene D, Kumsa B. Cystic echinococcosis in cattle slaughtered at Gondar Elfora export abattoir, northwest Ethiopia. J Parasit Dis. 2014;38(4):404-9. doi: 10.1007/s12639-013-0255-Z

28. Mandefro M, Tilahun B, Bayu Y, Zeryehun T. Prevalence of bovine hydatidosis and its economic importance in Adama municipal abattoir, eastern Ethiopia. Ethiop Vet J. 2019;23(1):24-41. doi: 10.4314/evj.v23i1.3

29. Akeberegn D, Alemneh T, Kassa T. The prevalence of bovine hydatidosis among slaughtered cattle at Debre Berhan municipal abattoir, north Shewa zone, Ethiopia. J Vet Sci Med. 2017;5(1):5.

30. Yohannes G, Masresha S. Study on the prevalence and associated risk factors of bovine hydatidosis in Hawassa municipal abattoir, Hawassa, Ethiopia. Gen Surg. 2019;1:42-6.

31. Anteneh M, Asrat M, Melkamu S. Prevalence and economic significance of hydatidosis in cattle slaughter at debretabore abattoir, north Gondar, Amhara region, Ethiopia. J Anim Res. 2015;5(3):473-7. doi: 10.5958/2277-940x.2015.00081.9

32. Hiko A, Ibrahim H, Agga GE. Abattoir based survey of bovine cystic echinococcosis in selected commercial abattoir in Ethiopia. J Vet Sci Technol. 2018;9(2):527. doi: 10.4172/2157-7579.1000527

33. Kumsa B, Mohammedzein A. Prevalence, organ distribution, risk factors, and financial losses of hydatid cysts in sheep and goats slaughtered in restaurants in Jimma, south western Oromia. Comp Clin Pathol. 2014;23(2):333-9. doi: 10.1007/s00580012-1619-y

34. Cardona GA, Carmena D. A review of the global prevalence, molecular epidemiology and economics of cystic echinococcosis in production animals. Vet Parasitol. 2013;192(1-3):10-32. doi: 10.1016/j. vetpar.2012.09.027

35. Mulatu M, Mekonnen B, Tassew H, Kumar A. Bovine hydatidosis in eastern part of Ethiopia. Momona Ethiop J Sci. 2013;5(1):107-14. doi: 10.4314/mejs. v5i1.85334 
36. Kebede N, Mekonnen H, Wossene A, Tilahun G. Hydatidosis of slaughtered cattle in Wolaita Sodo abattoir, southern Ethiopia. Trop Anim Health Prod. 2009;41(4):629-33. doi: 10.1007/s11250-008-9234-2

37. Kumsa B. Cystic echinococcosis in slaughtered cattle at Addis Ababa abattoir enterprise, Ethiopia. Vet Anim Sci. 2019;7:100050. doi: 10.1016/j. vas.2019.100050
38. Gemmell M, Lawson J. Epidemiology and control of hydatid disease. In: Thompson RCA, ed. Biology of Echinococcus and Hydatid Disease. London: George Allen \& Unwin; 1986.

39. Urquhart G, Armour J, Duncan J, Dunn A, Jennings F. Veterinary Parasitology. 2nd ed. Oxford: Long man scientific and technical press, UK; 1996.

(C) 2021 The Author(s); This is an open-access article distributed under the terms of the Creative Commons Attribution License (http:// creativecommons.org/licenses/by/4.0), which permits unrestricted use, distribution, and reproduction in any medium, provided the original work is properly cited. 